\title{
Repeatability of Objective Measurements on the Rear Legs of Dairy Cows ${ }^{1}$
}

\author{
P. O. Boisot, S. L. Rodriguez-Zas, and R. D. Shanks \\ Animal Sciences Laboratory, \\ University of Illinois Urbana-Champaign \\ 1207 W. Gregory Drive \\ $61801 \mathrm{IL}$
}

\begin{abstract}
The objective of this paper was to estimate the repeatability of objective measurements on the rear legs of dairy cows to see whether higher repeatability estimates could be obtained compared to the corresponding subjective linear score. Between September and November 1998, seven measurements of distance among dewclaw, hip, hock, pinbone, and thurl were taken on 73 cows from the University of Illinois dairy farm. Measurements were combined to define triangles and therefore angles reflecting rear leg structure. Three novice evaluators participated in the experiment, and, on a given day, two sets of measurements were taken by two evaluators. Cows were measured twice at a 1- to 4 -wk interval. Size, evaluator, and order of measurement were included in the model as fixed effects. Cow, interactions of cow $\times$ evaluator and cow $\times$ order of measurement were random effects included in the model. The model explained over $80 \%$ of the variation for each variable. Repeatability estimates of the length measurements ranged from 0.61 to 0.89 . Repeatability estimates of angles were much lower ranging from 0.00 to 0.24 . The variation in natural standing position of the cow hampered the accuracy of the objective measurements. Low estimates of repeatability for angles describing rear leg suggested that objective measurements by novice evaluators were not sufficiently reliable to potentially replace the subjective linear score for rear leg curvature determined by experts. Usefulness of further investigation to find objective measurements that would give a better description of rear legs conformation compared to the corresponding current type trait was questionable.
\end{abstract}

Received June 4, 2001.

Accepted February 7, 2002.

Corresponding author: R. D. Shanks; e-mail: rdshanks@uiuc.edu.

${ }^{1}$ This material is based upon work supported by the Cooperative State Research, Education and Extension Service, U. S. Department of Agriculture, under multi-state Project S-284. Any opinions, findings, conclusions, or recommendations expressed in this publication are those of the authors and do not necessarily reflect the view of the U. S. Department of Agriculture.
(Key words: dairy cow, rear leg, repeatability of objective measurement)

\section{INTRODUCTION}

Cows with high classification scores tended to have longer lifetime (Burnside and Wilton, 1970). Conformation in dairy cows was assessed by classifiers using a subjective linear scoring system (Foster et al., 1988). Cows were scored for several traits, and each trait was given a score from 1 to 50 points. The ranges of this measurement scale represented biological extremes for each trait (Holstein Association USA, 1996). Subjective linear traits may not be the best way to describe conformation in dairy cows because repeatability estimates were low for some traits, especially feet and legs (Gengler et al., 1997) and because variability existed between classifiers (Bowden, 1982). Gengler et al. (1997) found that repeatability estimates at different ages of linear type traits in Jerseys ranged from 0.29 (rear legsside view and foot angle) to 0.65 (rump angle and udder depth). Similar results were found for Holsteins by Misztal et al. (1995). The only study that compared subjective linear scores and corresponding objective measurements on the cow found reasonable relationships between objective and linear subjective traits, except for rear leg curvature (Vinson et al., 1982). Rear leg curvature was a trait of interest for dairy producers because differences in rear leg structure has been associated with differences in productive life (Boisot and Shanks, 2000). A first step would be to find objective measurements on the rear leg, especially angles, that would be more repeatable than the corresponding type trait. Further research to find objective measurements of rear leg curvature was needed.

The objectives of our study were first to collect objective measurements on the rear leg of dairy cows, different from the ones described by Vinson et al. (1982), then check whether higher repeatability estimates of objective measurements than those of Vinson et al. (1982) could be found. The ultimate objective was to assess whether any disadvantages of current linear 


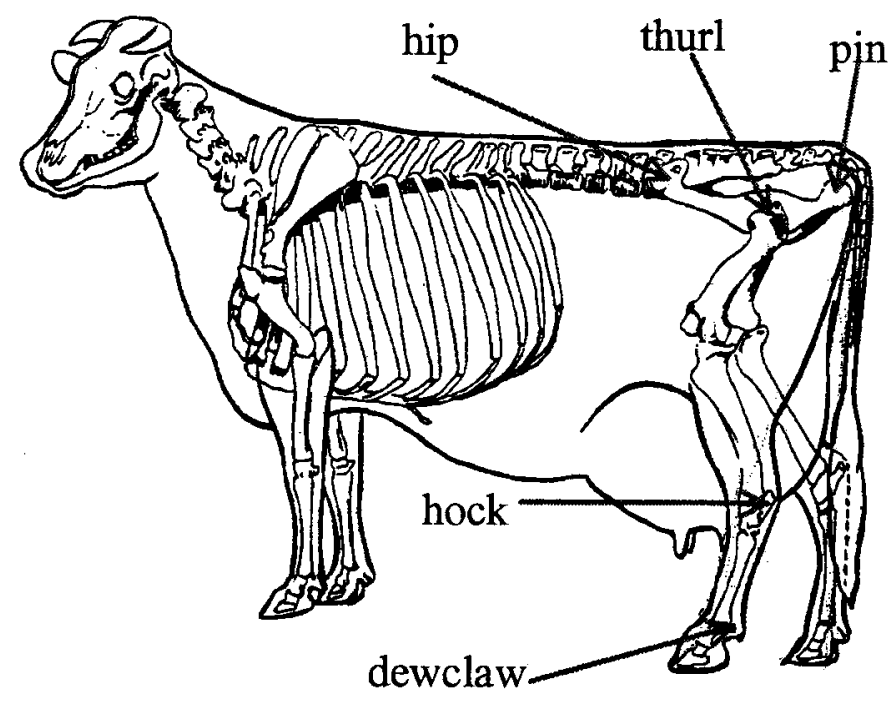

Figure 1. Dairy cow body parts and bone structure. (Source: Modified from Yapp, 1959.)

type score for rear leg curvature could be offset by these novel objective measurements.

\section{MATERIALS AND METHODS}

\section{Animals and Data Collection}

Seven length measurements on the rear legs of 73 cows at the University of Illinois dairy farm were collected. Measurements were taken among dewclaw, hip, hock, pinbone, and thurl from the right side of each cow with a soft tape. Figure 1 illustrates the body parts and bone structure of a dairy cow. Cows were housed in tie stalls, and a standard position of the cow was defined to collect measurements; cows had to be standing up, with the two rear legs parallel to be measured. Having the cow stand in the standard position was very difficult and resulted in some delay collecting the data. Some cows were also very nervous and could not stand still when measured. Before data collection, thurl and hip, which were the two most difficult points to define, were marked with a color chalk to make sure that the same point would be used to take the different measurements on a given day. Thurl was specifically hard to identify in fat cows. Measures were taken in inches with a precision of 0.5 inch and then converted to centimeters. Three evaluators participated in the experiment. Evaluators had no experience in judging or measuring cows. Evaluators were able to recognize body parts after one brief training session. Cows were measured twice between September and November 1998 by two of the three evaluators at any one time. The data collection resulted in 292 records: 73 cows were mea- sured twice by two evaluators $(73 \times 2 \times 2=292$ records $)$. Time between two sets of measurements ranged from 1 to $4 \mathrm{wk}$. This variability between two sets of measurement was due to the practical scheduling among evaluators to collect data. Furthermore, data collection was time consuming, and only a few cows could be measured on the same day. In this study, we were not interested in changes of body measurements over time. All the measurements taken were closely related to the bone structure of the cow. It was reasonable to assume that the bone structure of an adult cow does not change significantly over a period of 1 to $4 \mathrm{wk}$. For most of the cows, the same two evaluators collected the measurement at the two different times on the same cow (69 out of 73 cows). In some cases, only one evaluator among the two was able to repeat the measurement on the cow and, consequently, the third evaluator replaced the missing one (4 out of 73 cows).

\section{Computation of Angles Describing Rear Leg Curvature}

Nine angles, resulting from the combination of length measurements, were computed. The idea was to find angles that would describe the rear leg curvature of the cow (from posty to sickle).

Knowing the three sides of a triangle, its angles can easily be computed by using the "Law of cosine."

"Law of cosine": If a triangle has sides with lengths $\mathrm{a}, \mathrm{b}$, and $\mathrm{c}$, then the angles A, B, and C (A, B, and C being the angles between the sides $\mathrm{b}$ and $\mathrm{c}$, a and $\mathrm{c}$, and $a$ and $b$, respectively) of this triangle are:

$$
\begin{aligned}
& \mathrm{A}=\operatorname{Arcos}\left(\left(\mathrm{b}^{2}+\mathrm{c}^{2}-\mathrm{a}^{2}\right) /(2 \times \mathrm{b} \times \mathrm{c})\right) \\
& \mathrm{B}=\operatorname{Arcos}\left(\left(\mathrm{a}^{2}+\mathrm{c}^{2}-\mathrm{b}^{2}\right) /(2 \times \mathrm{a} \times \mathrm{c})\right) \\
& \mathrm{C}=\operatorname{Arcos}\left(\left(\mathrm{a}^{2}+\mathrm{b}^{2}-\mathrm{c}^{2}\right) /(2 \times \mathrm{a} \times \mathrm{b})\right)
\end{aligned}
$$

Angles of four triangles were evaluated. Triangles and angles computed are illustrated in Figures 2 to 4 .

Triangle: hip-dewclaw-hock (see Figure 2).

B1: angle formed by edges dewclaw-hip and hip-hock.

B2: angle formed by edges hip-dewclaw and dewclaw-hock.

B3: angle formed by edges dewclaw-hock and hockhip.

Triangle: thurl-dewclaw-hock (see Figure 3).

C1: angle formed by edges dewclaw-thurl and thurl-hock.

C2: angle formed by edges thurl-dewclaw and dewclaw-hock.

C3: angle formed by edges dewclaw-hock and hockthurl.

Triangle: pin-dewclaw-hock (see Figure 4).

D1: angle formed by edges dewclaw-pin and hock-pin. 


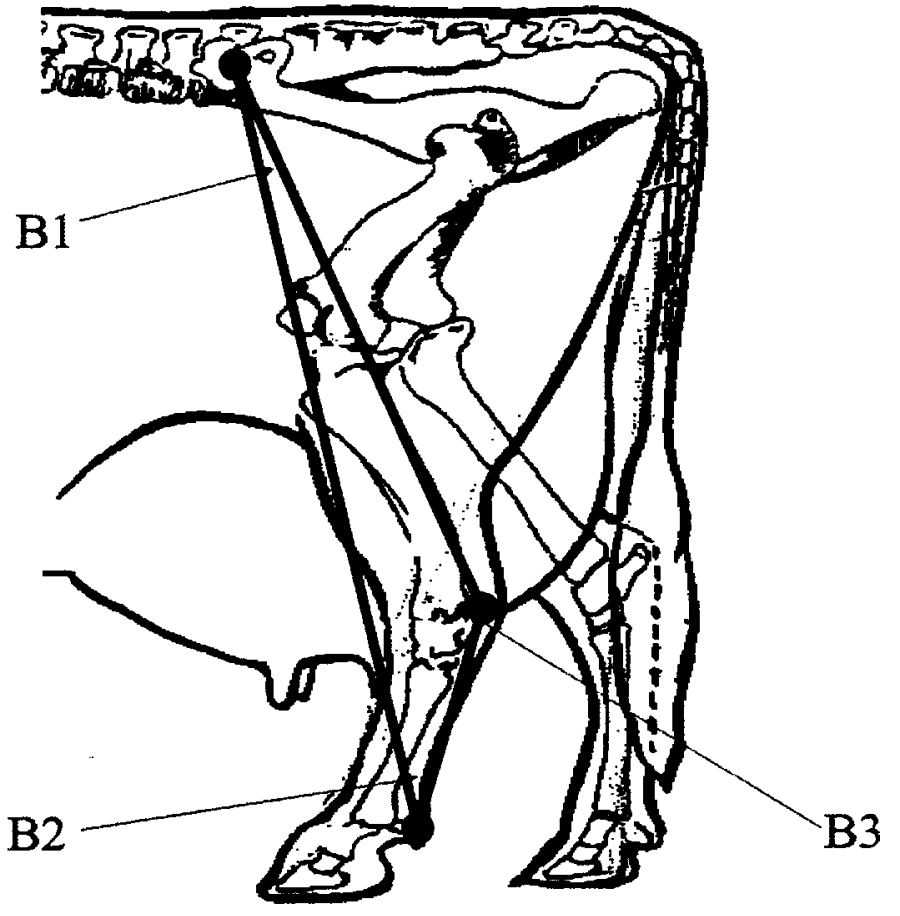

*Letters and numbers denote angles

Figure 2. Triangle hip-dewclaw-hock.*

D2: angle formed by edges pin-dewclaw and dewclaw-hock.

D3: angle formed by edges dewclaw-hock and hockpin.

The angles of interest were B3, C3, and D3 because of their potential to be good descriptors of rear leg curvature.

\section{Factors Considered}

Cow size. Measured cows were from different breeds: 42 Holsteins, 23 Jerseys, 5 Ayrshires, and 3 Brown Swiss. Because of the discrepancy in the number of individuals per breed and the small number of animals in breeds Brown Swiss and Ayrshires, a size effect was fitted in the model instead of a breed effect. Looking at the means per breed of our sample, Holsteins, Brown Swiss, and Ayrshires had a similar size and were grouped together as big cows. Jerseys were much smaller and were considered as small cows. We did not focus on only one breed because we were interested in measuring as many animals as possible and in assessing whether our measurements were repeatable on any type of cow. A restriction on the breed would have reduced the size of our dataset.

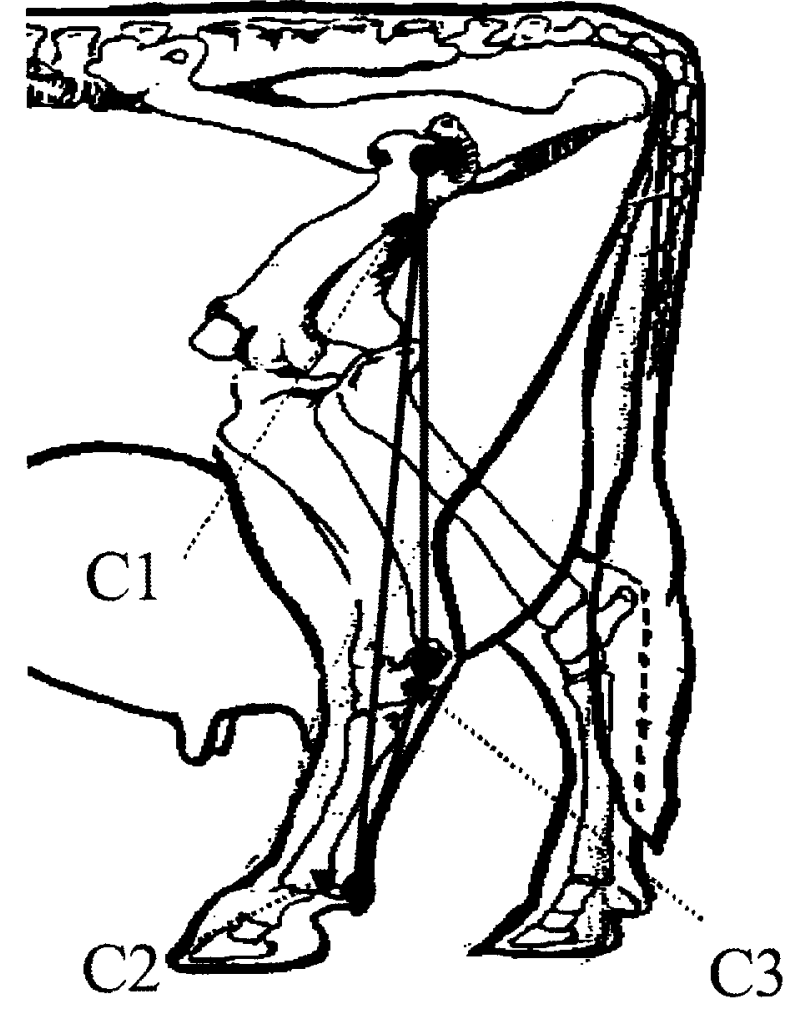

*Letters and numbers denote angles

Figure 3. Triangle thurl-dewclaw-hock.*

Evaluators. Three evaluators participated in the experiment. On a given day, a group of cows was measured by two of the three evaluators.

Order of measurement. Two sets of measurements at 1 - to 4 -wk intervals were taken on 73 cows.

\section{Statistical Analysis}

Estimation of repeatability of objective measurements. Model 1 was fitted:

$$
\begin{aligned}
& \mathrm{Y}_{\mathrm{ijkm}}=\mu+\mathrm{S}_{\mathrm{i}}+\mathrm{c}_{\mathrm{j}(\mathrm{i})}+\mathrm{E}_{\mathrm{k}}+(\mathrm{SE})_{\mathrm{ik}}+(\mathrm{cE})_{\mathrm{jk}(\mathrm{i})} \\
& +\mathrm{M}_{\mathrm{m}}+(\mathrm{SM})_{\mathrm{im}}+(\mathrm{cM})_{\mathrm{jm}(\mathrm{i})}+(\mathrm{EM})_{\mathrm{km}}+\varepsilon_{\mathrm{ijkm}}
\end{aligned}
$$

where,

$\mathrm{Y}_{\mathrm{ijkm}}$ represented the observation on the mth measurement of cow $\mathrm{j}$ of size $\mathrm{i}$ taken by evaluator $\mathrm{k}$,

$\mu$ represented the overall mean,

$\mathrm{S}_{\mathrm{i}}$ represented the fixed effect of size i, $\mathrm{i}=$ big or small cows,

$c_{j(i)}$ represented cow(size) the random effect of cow $j$ nested in size $i, j=1, \ldots, 23$ or $1, \ldots, 50$, 


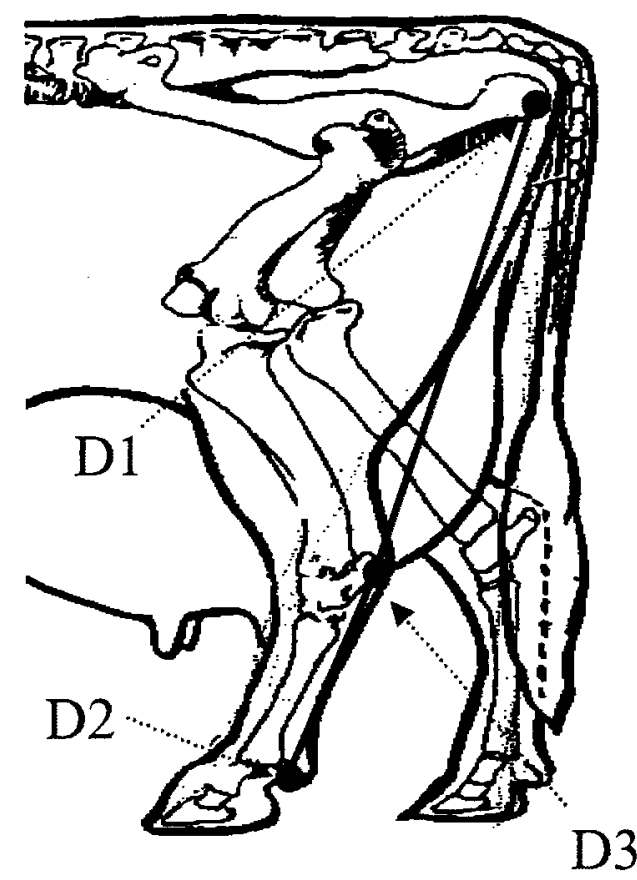

*Letters and numbers denote angles

i.e.: For convenience and clarity, the third side of the

triangle pin-dewclaw-hock was not drawn

Figure 4. Triangle pin-dewclaw-hock.*

$\mathrm{E}_{\mathrm{k}}$ represented the fixed effect of evaluator $\mathrm{k}, \mathrm{k}=1$, $\ldots, 3$,

$M_{m}$ represented the fixed effect for order of measurement $\mathrm{m}, \mathrm{m}=$ first or second,

$(\mathrm{SE})_{\mathrm{ik}},(\mathrm{cE})_{\mathrm{jk}(\mathrm{i})},(\mathrm{SM})_{\mathrm{im}},(\mathrm{cM})_{\mathrm{jm}(\mathrm{i})}$ and $(\mathrm{EM})_{\mathrm{km}}$ represented the two way interactions, and $\varepsilon_{\mathrm{ijkm}}$ represented the random error term.

In the full model, size was tested using cow(size) as the error term. The evaluator effect and the interaction of size by evaluator were tested using the interaction of cow(size) by evaluator as the error term. Order of measurement and interaction of size by order of measurement were tested using the interaction of cow(size) by order of measurement as the error term. Finally, the interaction of evaluator by measure was tested using the random error term. Nonsignificant terms $(P>$ 0.1 ) were eliminated from the full model. Residuals were assumed to have a mean of zero, to be independent and normally distributed. The final model used was then specific to each variable. Least squares means for size, evaluator, order of measurement, and the significant interactions were computed for each variable. Consequently, to compute the least squares means, the three fixed effects were kept in the model regardless of their significance. Proc MIXED (Little et al., 1996) was used to estimate cow variances and respective standard errors. Repeatability was computed as follows:

$$
\begin{gathered}
\text { Repeatability } \\
=\text { Between-cow variance/(Between-cow variance } \\
+ \text { Within-cow variance). }
\end{gathered}
$$

The between-cow variance is the variance of measurement on one cow to measurement on another cow. The within-cow variance is the variance of first measurement of a cow to second measurement on the same cow.

Estimation of phenotypic correlations among angles describing rear leg curvature. Phenotypic correlations between angles describing rear leg curvature (B3, C3, and D3) were computed, adjusting for size, order of measurement, and evaluator. The Manova option of Proc GLM (SAS, 1989) was used to get partial correlations adjusted for the three fixed effects.

\section{RESULTS}

\section{Descriptive Statistics on Objective Measurements and Angles}

A triangle can only be drawn when the sum of the length of the two smallest sides is greater than the longest one. If the length of the two smallest sides is equal to the longest one, we have a straight line instead of a triangle. In some cases, because of the inaccuracy of measurements, the length of the two smallest sides of a triangle was smaller than the longest one,

Table 1. Means, number of observations, standard deviation (SD), minimum (min) and maximum (max) for length measurements in centimeters.

\begin{tabular}{llrrrr}
\hline $\begin{array}{l}\text { Length } \\
\text { measurement }\end{array}$ & $\begin{array}{l}\text { Number of } \\
\text { observations }\end{array}$ & Mean & SD & Min & Max \\
\hline Hip to hock & 292 & 93.6 & 7.1 & 76.2 & 108.0 \\
Thurl to hock & 292 & 71.4 & 4.7 & 58.4 & 82.6 \\
Pin to hock & 292 & 79.4 & 6.7 & 64.8 & 95.3 \\
Hip to dewclaw & 292 & 126.3 & 8.8 & 106.7 & 142.2 \\
Thurl to dewclaw & 292 & 108.5 & 6.7 & 94.0 & 121.9 \\
Pin to dewclaw & 292 & 119.6 & 8.7 & 101.6 & 139.7 \\
Dewclaw to hock & 292 & 41.6 & 3.0 & 34.3 & 48.3 \\
\hline
\end{tabular}


Table 2. Means, number of observations, standard deviation (SD), minimum (min) and maximum ( $\max$ ) for angles in degrees.

\begin{tabular}{llrrrr}
\hline Angle & $\begin{array}{l}\text { Number of } \\
\text { observations }\end{array}$ & Mean & SD & Min & Max \\
\hline B1 & 292 & 13.4 & 2.0 & 5.8 & 19.3 \\
B2 & 292 & 31.5 & 5.1 & 12.5 & 19.9 \\
B3 & 292 & 135.1 & 7.1 & 110.8 & 161.7 \\
C1 & 290 & 11.7 & 3.5 & 0.0 & 54.8 \\
C2 & 290 & 20.6 & 6.4 & 0.0 & 180.0 \\
C3 & 290 & 147.7 & 9.8 & 104.6 & 16.6 \\
D1 & 244 & 6.7 & 3.9 & 0.0 & 34.4 \\
D2 & 244 & 13.1 & 7.8 & 0.0 & 180.0 \\
D3 & 244 & 160.2 & 11.7 & 129.0 & \\
\hline
\end{tabular}

and a triangle or even a straight line could not be drawn. Consequently, 244 (48 missing values) and 290 (2 missing values) observations out of 292 were available on the angles of the triangle pin-dewclaw-hock and thurldewclaw-hock, respectively.

Means, standard deviations, minimums, and maximums of the seven length measurements and the nine angles computed are presented in Tables 1 and 2, respectively. For the triangle thurl-dewclaw-hock, $\mathrm{C} 1$ and $\mathrm{C} 2 \mathrm{had}$ a minimum value of zero degrees in seven cases, which suggested a straight line instead of a triangle: distance $($ thurl-hock $)+$ distance $($ hock-dewclaw $)=$ distance (thurl-dewclaw). A similar remark can be made for the triangle pin-dewclaw-hock with zero degrees for D1 and D2 in 60 cases.

\section{Least Squares Means of Size, Evaluator, Order of Measurement and Significant Interactions}

The complete model accounted for more than $90 \%$ of the variation for length measurements and more than $80 \%$ of the variation for angles. Least squares means of the fixed effects of size, evaluator, and order of measurement of the seven length measurements and nine angles are presented in Tables 3 and 4 . Size was significant for all measurements $(P \leq 0.01)$ and for all angles, except those of the triangle pin-dewclaw-hock. Evaluator was significant for most of the length measurements, excluding hip, thurl, and pin to dewclaw. The evaluator effect was significant for all angles $(P \leq$ 0.01 ). Significant differences between first and second measurement were only observed for distance dewclaw to hock. The order of measurement effect was significant for all angles except the angles of the triangle hipdewclaw-hock. The interaction of size by evaluator was significant $(P \leq 0.01)$ for the angles D1, D2, and D3.

\section{Repeatability Estimates of Objective Measurements and Angles}

Cow variances with corresponding standard errors and repeatability estimates for the length measurements and angles are presented in Tables 5 and 6. Repeatability estimates for length measurements ranged from 0.61 (dewclaw to hock) to 0.89 (thurl-dewclaw). Repeatability estimates for angles were much lower, ranging from 0.00 (D1) to $0.24(\mathrm{C} 1)$. Cow variance

Table 3. Least squares means and standard errors (SE) of length measurements for the different fixed effects in centimeters.

\begin{tabular}{|c|c|c|c|c|c|c|c|c|c|c|c|c|c|c|c|c|c|}
\hline \multirow{3}{*}{$\begin{array}{l}\text { Length } \\
\text { measurement }\end{array}$} & \multicolumn{5}{|c|}{ Size } & \multicolumn{7}{|c|}{ Evaluator $^{1}$} & \multicolumn{5}{|c|}{ Measure } \\
\hline & \multicolumn{2}{|c|}{ Big } & \multicolumn{2}{|c|}{ Small } & \multirow[b]{2}{*}{$P$ value } & \multicolumn{2}{|c|}{ E1 } & \multicolumn{2}{|c|}{$\mathrm{E} 2$} & \multicolumn{2}{|c|}{ E3 } & \multirow[b]{2}{*}{$P$ value } & \multicolumn{2}{|c|}{ First } & \multicolumn{2}{|c|}{ Second } & \multirow[b]{2}{*}{$P$ value } \\
\hline & $\overline{\mathrm{X}}$ & $\mathrm{SE}$ & $\overline{\mathrm{X}}$ & $\mathrm{SE}$ & & $\bar{X}$ & $\mathrm{SE}$ & $\overline{\mathrm{X}}$ & $\mathrm{SE}$ & $\overline{\mathrm{X}}$ & $\mathrm{SE}$ & & $\overline{\mathrm{X}}$ & $\mathrm{SE}$ & $\overline{\mathrm{X}}$ & $\mathrm{SE}$ & \\
\hline Hip to hock & 97.6 & 0.5 & 84.7 & 0.7 & $* *$ & 90.4 & 0.1 & 92.0 & 0.1 & 91.0 & 0.1 & $* *$ & 91.0 & 0.2 & 91.3 & 0.2 & \\
\hline Thurl to hock & 73.7 & 0.4 & 66.0 & 0.5 & $* *$ & 69.5 & 0.3 & 70.7 & 0.3 & 69.4 & 0.3 & $* *$ & 69.8 & 0.2 & 69.9 & 0.2 & \\
\hline Pin to hock & 81.8 & 0.7 & 73.6 & 1.1 & $* *$ & 76.9 & 0.2 & 78.7 & 0.2 & 77.6 & 0.2 & $* *$ & 77.5 & 0.2 & 77.9 & 0.2 & \\
\hline Hip to dewclaw & 131.5 & 0.5 & 114.9 & 0.8 & $* *$ & 123.1 & 0.2 & 123.3 & 0.2 & 123.4 & 0.2 & & 123.0 & 0.3 & 123.5 & 0.3 & \\
\hline Thurl to dewclaw & 112.3 & 0.5 & 100.2 & 0.7 & $* *$ & 106.2 & 0.1 & 106.3 & 0.1 & 106.3 & 0.1 & & 106.3 & 0.2 & 106.2 & 0.2 & \\
\hline Pin to dewclaw & 124.0 & 0.8 & 110.1 & 1.1 & $* *$ & 116.6 & 0.2 & 117.1 & 0.2 & 117.5 & 0.2 & & 117.0 & 0.2 & 117.1 & 0.2 & \\
\hline Dewclaw to hock & 43.4 & 0.2 & 37.8 & 0.2 & $* *$ & 40.4 & 0.1 & 41.0 & 0.2 & 40.3 & 0.2 & $* *$ & 40.4 & 0.1 & 40.8 & 0.1 & $*$ \\
\hline
\end{tabular}

$* P<0.01$.

$* * P<0.001$.

${ }^{1} \mathrm{E} 1, \mathrm{E} 2$, and E3 represent evaluators one, two and three. 
Table 4. Least squares means and standard errors (SE) of angles for the fixed effects in degrees.

\begin{tabular}{|c|c|c|c|c|c|c|c|c|c|c|c|c|c|c|c|c|c|}
\hline \multirow[b]{3}{*}{ Angle } & \multicolumn{5}{|c|}{ Size } & \multicolumn{7}{|c|}{ Evaluator } & \multicolumn{5}{|c|}{ Measure } \\
\hline & \multicolumn{2}{|c|}{ Big } & \multicolumn{2}{|c|}{ Small } & \multirow[b]{2}{*}{$P$ value } & \multicolumn{2}{|c|}{ E1 } & \multicolumn{2}{|c|}{ E2 } & \multicolumn{2}{|c|}{ E3 } & \multirow[b]{2}{*}{$P$ value } & \multicolumn{2}{|c|}{ First } & \multicolumn{2}{|c|}{ Second } & \multirow[b]{2}{*}{$P$ value } \\
\hline & $\overline{\mathrm{X}}$ & $\mathrm{SE}$ & $\overline{\mathrm{X}}$ & SE & & $\overline{\mathrm{X}}$ & SE & $\overline{\mathrm{X}}$ & $\mathrm{SE}$ & $\overline{\mathrm{X}}$ & $\mathrm{SE}$ & & $\overline{\mathrm{X}}$ & SE & $\overline{\mathrm{X}}$ & $\mathrm{SE}$ & \\
\hline B1 & 13.5 & 0.2 & 13.0 & 0.3 & $*$ & 12.8 & 0.3 & 14.2 & 0.3 & 12.8 & 0.3 & ** & 13.3 & 0.1 & 13.4 & 0.1 & \\
\hline B2 & 31.8 & 0.5 & 30.3 & 0.7 & $*$ & 29.8 & 0.5 & 33.4 & 0.5 & 30.0 & 0.5 & $* *$ & 30.9 & 0.4 & 31.3 & 0.4 & \\
\hline B3 & 134.6 & 0.6 & 136.7 & 0.9 & $*$ & 137.4 & 0.7 & 132.4 & 0.8 & 137.2 & 0.8 & $* *$ & 136.0 & 0.5 & 135.4 & 0.5 & \\
\hline $\mathrm{C} 1$ & 11.9 & 0.3 & 10.9 & 0.5 & $* *$ & 10.4 & 0.1 & 13.0 & 0.1 & 10.8 & 0.1 & $* *$ & 10.8 & 0.2 & 12.0 & 0.2 & $*$ \\
\hline D1 & 6.6 & 0.3 & 6.2 & 0.5 & & 5.7 & 1.0 & 9.0 & 1.1 & 4.0 & 1.2 & & 5.9 & 0.4 & 7.0 & 0.4 & $*$ \\
\hline D2 & 12.7 & 0.6 & 12.3 & 0.9 & & 10.1 & 2.1 & 17.7 & 2.2 & 8.7 & 2.3 & $* *$ & 11.5 & 0.7 & 13.5 & 0.7 & $*$ \\
\hline D3 & 160.7 & 0.9 & 161.5 & 1.3 & & 163.4 & 3.1 & 153.3 & 3.3 & 166.7 & 3.5 & $* *$ & 162.7 & 1.1 & 159.6 & 1.1 & * \\
\hline
\end{tabular}

$$
\begin{aligned}
& * P<0.01 . \\
& * * P<0.001 .
\end{aligned}
$$

for D2 and D3 was found to be zero and, consequently, corresponding standard errors were not estimable. This last result suggests that none of the variability of the angles of the triangle pin-dewclaw-hock was explained by the variability of cow.

\section{Phenotypic Correlations Among Angles Describing Rear Leg Curvature}

Phenotypic correlations among angles describing rear leg curvature are presented in Table 7 . When adjusting for size, order of measurement and evaluator, 294 observations were used because the Manova option of proc GLM requires an equal number of observations for each variable. Correlations between B3 and C3 and between C3 and D3 were positive. The correlation between B3 and D3 was not significantly different from zero when adjusted for the three fixed effects.

\section{DISCUSSION}

Significant interactions between size with evaluator for the angles D1, D2, and D3, showed that evaluators were not consistent in their technique when measuring big and small cows for these traits. Significance of size on all length measurements was not surprising and justified our grouping of cow breeds. On the other hand, significance of size for almost all the angles computed was more unexpected. Looking at the least squares means, our results suggest that small cows have more posty legs than bigger cows. This study was done on a small number of cows, and this result may only be true for our sample. The small cows were all Jersey cows and the more posty leg could just be a characteristic of the breed.

Significant differences between evaluators for most of the variables showed that each evaluator had a different way of measuring cows. An effort was made to have consistency and use the same points when taking the measurements. Because a specific body part like hock or hip, is not defined by a single point but by an area of several inches, evaluators might have taken slightly different points when collecting measurements. As an example, a measurement involving hock could be taken at the top, middle, or bottom of the articulation. The impossibility to draw triangles in certain cases suggests that each evaluator was not even consistent when taking measurements from a specific body part. A very simple illustration can be shown with the triangle hiphock-dewclaw. Only 244 angles could be computed out

Table 5. Cow variances and standard errors (SE), and repeatability estimates for length measurements.

\begin{tabular}{lccc}
\hline $\begin{array}{l}\text { Length } \\
\text { measurement }\end{array}$ & $\begin{array}{l}\text { Cow } \\
\text { variance } \\
\left(\mathrm{cm}^{2}\right)\end{array}$ & SE & Repeatability \\
\hline Hip to hock & 9.03 & 1.74 & 0.76 \\
Thurl to hock & 4.77 & 1.03 & 0.63 \\
Pin to hock & 23.81 & 4.32 & 0.83 \\
Hip to dewclaw & 10.65 & 2.19 & 0.78 \\
Thurl to dewclaw & 10.45 & 1.94 & 0.89 \\
Pin to dewclaw & 26.32 & 4.90 & 0.88 \\
Dewclaw to hock & 1.03 & 0.19 & 0.61 \\
\hline
\end{tabular}


Table 6. Cow variances, standard errors (SE), and repeatability estimates for angles.

\begin{tabular}{lcll}
\hline Angle & $\begin{array}{l}\text { Cow variance } \\
\left(\text { degrees }^{2}\right)\end{array}$ & SE & Repeatability \\
\hline B1 & 0.64 & 0.27 & 0.22 \\
B2 & 4.48 & 1.92 & 0.23 \\
B3 & 8.14 & 3.56 & 0.20 \\
C1 & 15.29 & 6.96 & 0.24 \\
C2 & 6.56 & 2.99 & 0.22 \\
C3 & 1.86 & 0.85 & 0.23 \\
D1 & 0.06 & 0.81 & 0.02 \\
D2 & 0.00 & $\mathrm{NE}^{1}$ & 0.00 \\
D3 & 0.00 & $\mathrm{NE}$ & 0.00 \\
\hline
\end{tabular}

${ }^{1} \mathrm{NE}=$ Standard errors of cow variances are not estimable when cow variances are zero.

of 292 observations. This could happen if, for example, the distance hip to hock was taken from the top of the hock to the hip and the distance hock to dewclaw was taken from the bottom or the middle of the hock. Part of this inconsistency can also be due to the nervousness of some cows that could hardly stand still when measured.

No significant difference between first and second measurement was found for six out of seven length measurements, but the order of measurement was significant for six out of nine angles. This last result might be related to the difficulty of getting the cows in the standard position. The same measurement on the same cow at two different times could be quite different if the cow was not standing in exactly the same way. From the least squares means, the second measurement was rarely different by more than $4 \%$ and never by more than $9 \%$ compared with the first measurement for angles of the triangles hip-dewclaw-hock, and thurldewclaw-hock, which seemed reasonable. Increases around $20 \%$ were found in the second measurement for the angles of the triangle pin-dewclaw-hock. The angles of the triangle pin-dewclaw-hock were not repeatable (repeatability close to zero), which is consistent with the greater variability associated with order of measurement.

Repeatability estimates for length measurements were similar to those reported by Vinson et al. (1982)

Table 7. Correlations between angles describing rear leg curvature. ${ }^{1}$

\begin{tabular}{llll}
\hline & B3 & C3 & D3 \\
\hline B3 & 1.00 & $0.35^{* * *}$ & 0.01 \\
C3 & $0.47^{* * *}$ & 1.00 & $0.26^{* * *}$ \\
D3 & $0.12^{*}$ & $0.33^{* * *}$ & 1.00 \\
\hline
\end{tabular}

${ }^{1}$ Phenotypic correlation adjusted for size, evaluator and order of measurement (above diagonal). Phenotypic correlation not adjusted (below diagonal).

$* P<0.05$.

$* * * P<0.001$ (significantly different from zero).
(0.72 to 0.97 ) on 297 Holstein cows. These authors reported a larger repeatability estimate for the angle describing rear leg curvature (0.45) than those found in this study (0.00 to 0.24). Angles from Vinson et al. (1982) were defined from one length measurement to the vertical axis, so only one measurement error was associated with them. Our angles were obtained from three length measurements, so three measurement errors were associated with them. This different approach may explain why our repeatability estimates of angles were lower compared with Vinson et al. (1982) study. The low repeatability estimates obtained for the distance between hock and thurl could be due to the difficulty in identifying these two points. Standard errors of cow variances were moderate for length measurements and high for angles. The accuracy of our repeatability estimates for angles was low. Repeatability estimates of length measurements at 1- to 4-wk intervals were higher than repeatability estimates between lactations for type traits obtained by Misztal et al. (1995) and Gengler et al. (1997), which were estimated by using data on more than 20,000 cows and evaluated by experts (classifiers). Length measurements of the present study were not directly valuable to describe leg conformation but angles obtained from them were of interest. Repeatability estimates of angles describing rear leg curvature at 1- to 4-wk intervals were also much lower than repeatability estimates for rear legs-side view between lactations ( 0.00 to 0.24 against 0.29 to 0.34 ). Low repeatability estimates for angles suggested that our measurements were strongly influenced by the standing position of the cow. As discussed before, getting the cow in the standard position was very difficult. As a consequence, a difference of more than 10 degrees could be found on the same rear leg angle of the same cow between two sets of measurements.

Our objective measurements on rear leg curvature were less repeatable than the linear type trait rear legs-side view, and, consequently, did not improve the accuracy on the description of rear leg conformation. 
The variation in the standing position of a cow may have hampered the accuracy of the objective measurements, explaining the low repeatability estimates found for angles. Measurements were also collected by novices, which may have increased measurement errors.

\section{CONCLUSION}

Results were based on a few cows, and standard errors of cow variances were large, suggesting that generalization of our results has to be taken cautiously. However, problems encountered measuring 73 cows would be similar at a larger scale. The alternative objective measurements for rear leg curvature in this study were long and inconvenient to collect (requiring the cow to be tied up and two people to take the measurements) and inaccurate. Repeatability estimates of our objective measurements were smaller than desired. None of the disadvantages of linear type traits for rear leg curvature have been improved. These objective measurements were consequently not sufficiently reliable to potentially replace subjective linear scores for rear leg curvature. Finding objective measurements to better describe leg conformation than corresponding, expertappraised type traits will be difficult.

\section{ACKNOWLEDGMENTS}

The authors wish to recognize Abby Mathewson and Shawn Shrum, two undergraduate students majoring in Animal Sciences at the University of Illinois at Urbana-Champaign, who helped collect the data.

\section{REFERENCES}

Boisot, P. O., and R. D. Shanks. 2000. Feet and leg structures associated with changes in productive life in dairy cows. J. Dairy Sci. 83(Suppl. 1):51. (Abstr.)

Bowden, V. 1982. Type classification in dairy cattle: A review. Anim. Breed. Abstr. 50:148-192.

Burnside, E. B., and J. W. Wilton. 1970. Anatomical traits as they relate to productive utility. J. Dairy Sci. 53:837-846.

Foster, W. W., A. E. Freeman, and P. J. Berger. 1988. Linear type traits analysis with genetic parameter estimation. J. Dairy Sci. 71:223-231.

Gengler, N., G. R. Wiggans, J. R. Wright, H. D. Norman, and C. W. Wolfe. 1997. Estimations of (co)variances components for Jersey type traits using repeatability model. J. Dairy Sci. 80:1801-1806.

Holstein Association USA. 1996. Linear classification system. Brattleboro, VT. 20 pp.

Little, R. C., G. A. Milliken, W. W. Stroup, and R. D. Wolfinger. 1996. SAS System for Mixed Model. SS Institute Inc., Cary, NC. 633 pp.

Misztal, I., K. Weigel, and T. J. Lawlor. 1995. Approximation of estimates of (co)variances components with multiple-trait restricted maximum likelihood by multiple diagonalization for more than one random effect. J. Dairy Sci. 78:1862-1872.

SAS/STAT User's Guide, Version 6 Fourth Edition. 1989. SAS Inst., Inc., Cary, NC.

Vinson, W. E., R. E. Pearson, and L. P. Johnson. 1982. Relationships between linear descriptive type traits and body measurements. J. Dairy Sci. 65:995-1003.

Yapp, W. 1959. Dairy Cattle Judging and Selection. John Wiley and Son, Inc., New York. 324 pp. 